Bes, R.E., Berg, B. van den. Ranking sources of hospital quality information for orthopedic surgery patients: consequences for the system of managed competition. The Patient: PatientCentered Outcomes Research: 2013, 6(2), 75-80 nivel

\begin{tabular}{|l|l|}
\hline $\begin{array}{l}\text { Postprint } \\
\text { Version }\end{array}$ & 1.0 \\
\hline Journal website & http://link.springer.com/article/10.1007\%2Fs40271-013-0011-6 \\
\hline Pubmed link & $\underline{\text { http://www.ncbi.nlm.nih.gov/pubmed/23549928 }}$ \\
\hline DOI & 10.1093/intqhc/mzt024 \\
\hline
\end{tabular}

This is a NIVEL certified Post Print, more info at http://www.nivel.eu

\title{
Ranking Sources of Hospital Quality Information for Orthopedic Surgery Patients: Consequences for the System of Managed Competition
}

\author{
ROMY EVELIEN BES • BERNARD VAN DEN BERG
}

\begin{abstract}
Background Healthcare quality information is crucial for the system of managed competition. Within a system of managed competition, health insurers can selectively contract care providers and are allowed to channel patients towards contracted providers. The idea is that insurers have a stronger bargaining position compared to care providers when they are able to channel patients. In the Dutch system of managed competition that was implemented in 2006, channelling patients to preferred providers has not yet been very successful. Empirical knowledge of which sources of hospital quality information they find important may help us to understand how to channel patients to preferred providers.

Objectives The objective of this survey was to measure how patients rank various sources of information when they compare hospital quality in a system of managed competition.

Methods A written survey was conducted among clients of a large Dutch health insurance company. These clients underwent orthopedic surgery on the hip or knee no longer than 12 months ago.

Results Two major players within a system of managed competition-health insurers and the government-were not seen as important sources of hospital quality information.

In contrast, own experience and general practitioners (GPs) were seen as the most important sources of hospital quality information within the Dutch system of managed competition.

Conclusions Health insurers should take the main finding - that GPs are the most important source of hospital quality information-into account when they contract care providers and develop strategies for channeling patients towards preferred providers. A well-functioning system of managed competition will
\end{abstract}


Bes, R.E., Berg, B. van den. Ranking sources of hospital quality information for orthopedic surgery patients: consequences for the system of managed competition. The Patient: PatientCentered Outcomes Research: 2013, 6(2), 75-80

benefit patients, as it involves incentives for care providers to increase healthcare quality and to produce at the lowest cost per unit of quality.

\section{Key points for decision makers}

- Although the health insurer and the government are the two most important players within the Dutch system of managed competition, patients rank them as the least important source of quality information.

- Health insurers within a system of managed competition should consider that patients find GPs to be the most important source of quality information when developing strategies to channel patients to preferred providers.

\section{INTRODUCTION}

A new health insurance act in the Netherlands, introduced in 2006, places great emphasis on consumer and patient choice and competition among insurers. The new act, which replaced the former public and private health insurance systems, is part of a broader reform of the Dutch healthcare system based on the principles of managed competition [1]. The introduction of the Health Insurance Act is arguably the most significant health policy reform in Europe in decades [2]. Under the new law, all citizens are required to purchase a basic health insurance policy. They can choose any insurer they like. Competing health insurance companies are required to accept all applicants during a yearly open enrolment period.1 The government determines the content of the basic health insurance package (medical care except long-term care) that insurers have to offer. Basic benefits are not defined in terms of providers but in terms of functions of care [1]. This offers flexibility to health insurers to design their products and contracts with care providers to better appeal to the preferences of the consumers [2]. Health insurers are allowed to selectively contract care providers, which could lead to more competition between care providers. The central idea of the new system is that provider competition either exerts a downward pressure on prices/costs given a certain level of healthcare quality or that it has better incentives to improve or differentiate healthcare quality, potentially at higher prices/costs, as long as consumers and patients are willing to pay for better quality or diversification [2]. In the Dutch healthcare system, general practitioners (GPs) typically act as gatekeepers for medical specialists/hospital care, partly to avoid the unnecessary use of relatively expensive care [3]. In practice, a GPs' gatekeeper function implies that the GP decides whether specialist treatment is necessary. If it is, the patient chooses a hospital.2 Note that it is not necessary for GPs to act as gatekeepers for the system of managed competition to work.

A necessary condition for the system of managed competition to work is that quality information about care providers and health insurers is available. Without quality information, health insurers can only negotiate with care providers on prices, and without this information consumers cannot choose between the insurers based on their quality of contracted care or on the quality of the service they provide. A complementary requirement is that insurers use this information to purchase healthcare, and consumers and patients use this information to choose a health insurer and a care provider when they need care. If consumers and patients do not 
Bes, R.E., Berg, B. van den. Ranking sources of hospital quality information for orthopedic surgery patients: consequences for the system of managed competition. The Patient: PatientCentered Outcomes Research: 2013, 6(2), 75-80

use quality information when making decisions, it is likely that the managed competition will just become a price competition involving a race to the bottom. However, if they do use this information, the system of managed competition involves incentives for care providers to become conscious of the costs and the quality of the services they provide [2]. In Dutch healthcare, healthcare quality information is provided by different sources, such as the government, health insurers, and the media. An unanswered question within managed competition is: what sources of quality information do patients find important when they compare care providers; for example, when choosing a hospital ${ }_{3}$ Surprisingly, there has been limited discussion of this question, even though the answer is important within managed competition, where insurers have to find ways to channel patients to preferred care providers, 4 for the government (the regulator of the managed competition system), and ultimately for the patients, as the healthcare reform only involves incentives to improve quality if quality information is available and if patients use available quality information. Providing quality information via a source that consumers and patients find unimportant might therefore limit the potential impact of the system of managed competition in terms of involving incentives to improve quality. The objective of this preliminary study is to present initial evidence on patients' ranking of sources of information when they compare hospital quality from a small-scale survey.5

\section{BACKGROUND}

In the Netherlands, the price of hospital care was regulated before the new health insurance act went into effect. Price regulation then decreased slowly, before it decreased dramatically in 2012 (and will continue to do so). This implies that health insurers can negotiate with hospitals on the price of hospital care. As described above, in theory, the system of managed competition involves incentives for health insurers to negotiate with hospitals on the price and quality of provided care. The government slowly decreased price regulation in hospital care to allow the health insurers and hospitals to get used to negotiating, as health insurers mainly negotiated with hospitals about the size of the budget before the introduction of the new system in 2006.

Allowing the insurers to negotiate on prices is supposed to lead to increased competition between hospitals and ultimately between health insurers. It is anticipated that health insurers will increasingly implement selective contracting and preferred provider arrangements, as the literature suggests that the bargaining power of health insurers depends on their ability to channel patients towards preferred providers $[4,5]$. So far, only a few insurers have experimented with channeling patients [6]. Other insurers seem worried about losing their reputation and enrollees when arranging preferred provider arrangements.

As mentioned in the "Introduction,"' different sources of healthcare quality information are available in Dutch healthcare. The government developed a website and has an inspectorate to monitor care providers; a newspaper and magazine produce annual national rankings; and health insurers have imported the American Consumer Assessment of Health Plan Surveys [7]. Although the website supervised by the Dutch government is frequently visited (in 2008, $10 \%$ of the Dutch population visited this website) [8], in practice patients often choose the hospital that is closest to their home [9-11]. This could suggest insufficient availability of quality 
Bes, R.E., Berg, B. van den. Ranking sources of hospital quality information for orthopedic surgery patients: consequences for the system of managed competition. The Patient: PatientCentered Outcomes Research: 2013, 6(2), 75-80

information, or availability of quality information that is perceived as insufficient to encourage patients to choose hospitals that are located further away.

\section{METHODS}

\subsection{Sample Selection and Characteristics}

The sample was identified based on the client list of a large Dutch health insurance company. The individuals had to have been the companies' clients for more than a year, and they had to have undergone orthopedic surgery on the hip or knee joint no longer than one year previously. Orthopedic surgery was chosen because this care can be planned (no emergency), so patients had time to choose a hospital.

Also, at the time the survey was conducted, this type of care was already in the socalled B-segment, implying that the prices were already deregulated by the government.

Three hundred ninety-five individuals met these criteria.

In June 2009, the selected individuals received a written questionnaire with an informed consent form and a return envelope. The response rate was $27.3 \%(\mathrm{n}=$ 108). This is comparable with similar surveys in the Netherlands [2].

Even lower response rates of around $10 \%$ have been reported when an alternative study design was used in which written surveys were randomly distributed over households [12]. The mean age of the respondents was 61.4 years (SD 15.3), and $43.5 \%$ of the respondents were male. The respondents were older than the mean age of the adult Dutch population (47.5 years) [13], obviously because problems with hip and knee joints are more common in older adults.

\subsection{Survey Questions}

The respondents were asked to indicate which source of hospital quality information they found most important.

Questions were hypothetical, as we asked the respondents to imagine they needed care and had to find information about hospital quality. Respondents could choose between: national rankings in newspapers/magazines, their health insurance company, friends/family, their GP, government website, own experience, and patient/consumer organizations.

${ }_{6} \mathrm{We}$ also asked the respondents to indicate the least important source of hospital quality information. This potentially provides extra information: not being indicated as most important does not necessarily imply that respondents consider this source to be least important, so defining the least important source of hospital quality information provides a validity check of the first question. Exact survey questions are presented in the Appendix.7 Proportion tests were performed to test whether the differences in importance were statistically significant.

\section{RESULTS}

Table 1 presents the results. The first column shows that GPs and own experience are very popular sources of hospital quality information (34 and $43 \%$ ). The table also suggests that, despite their central roles as the regulator and

\section{[TABLE 1]}

purchasers of healthcare within the system of managed competition, respectively, the government (via websites, $5.6 \%$ ) and insurers (3.7 \%) were not usually seen as 
Bes, R.E., Berg, B. van den. Ranking sources of hospital quality information for orthopedic surgery patients: consequences for the system of managed competition. The Patient: PatientCentered Outcomes Research: 2013, 6(2), 75-80

important sources of hospital quality information. The second column shows that the least important source of hospital quality information was national rankings in a newspaper or journal (42.6\%). However, friends/family (19.4\%), government websites $(16.7 \%)$, and health insurers (15.7\%) were also frequently considered unimportant sources of hospital quality information. Overall, GPs, own experience, and patient/consumer organizations were most frequently cited as important sources. In contrast, the rankings provided by national newspapers and journals, friends/family, health insurers, and government websites did not seem popular. Proportion tests showed that the difference in importance between GPs and own experience was not statistically significant $(\mathrm{p}=0.14)$, but the differences in importance between GPs and the other sources, and between own experience and the other sources, were statistically significant $(\mathrm{p}<0.001)$. National rankings were most frequently cited as least important (significant; $\mathrm{p}<0.001$ ). Health insurers, friends/family, and government websites did not differ in importance from each other, but they did differ statistically significantly from the other sources ( $p<0.001$ ).

\section{CONCLUSION AND DISCUSSION}

The work described in this paper was performed to obtain initial evidence on how patients rank various sources of hospital quality information when they compare hospitals within a system of managed competition. Our results suggest that the quality information provided by two main players within the system of managed competition - health insurers and the government - are not considered important sources of hospital quality information. In contrast, own experience and GPs are considered by far the most important sources of quality information.

Our results are in line with previous Dutch findings that are not published in the international literature [14] and other literature. De Groot et al. [15] found in the Netherlands that patients chose hospitals based mainly on their own experience and GP advice. Internationally, Marshall et al. found that people rarely search for performance data because they do not understand or trust it, so it has only a small impact on their decision making [16]. Also, people tend to make easy decisions (e.g., by relying on the experience of other people or their own past experiences, rather than using comparative quality data) [17]. Previous research on the type of quality information that patients find important also confirms the importance of own experience.

Furthermore, hospital reputation, hospital atmosphere, patient ratings, performance on preventive care, and experiences of friends and family are found to be important [18-20].

Channeling patients to preferred providers will give the health insurers more bargaining power, and is supposed to involve incentives for care providers to increase quality and become cost conscious. This will eventually be beneficial for the Dutch healthcare system and for the patients.

Health insurers should take the main finding - that GPs are a very important source of hospital quality information - into account when they contract care providers, and develop strategies on how to channel patients towards preferred providers. They could try to convince GPs of their strategy in contracting hospitals. Alternatively, they could take over GPs, by employing them. However, this strategy may have a negative impact on the value patients attribute to the advice from their GP. This could lead to people changing insurers or GPs. Also, health insurers could invest in 
Bes, R.E., Berg, B. van den. Ranking sources of hospital quality information for orthopedic surgery patients: consequences for the system of managed competition. The Patient: PatientCentered Outcomes Research: 2013, 6(2), 75-80

gathering knowledge about how GPs refer their patients. What types of quality nivel information do GPs use, and what potential is there for improvement? A limitation of our study is that we did not measure the importances of different types of quality information, which is clearly an interesting area for future research. Future research could also add hospital websites as a quality source and employ choice-based approaches such as conjoint or discrete choice experiments. This would enable patient trade-offs to be quantified. To complement this, respondents could be allowed to use different sources of quality information for various types of quality information, such as structure, process, and outcomes.

Another interesting challenge for future research would be to find out why some sources are considered important and others unimportant. A strength of this study is the inclusion of patients who recently underwent orthopedic surgery, as they have recently chosen a hospital. Their ranking based on experience is informative. However, although the response rate was comparable with those encountered in similar studies, it is still low. As we do not have data on the non-respondents, we cannot rule out selective nonresponse, so it is important to be very careful about generalizing our results. We also emphasise that our respondents are clients of an insurer with enrollees concentrated in the north-west. In this part of the Netherlands, there are rural areas with only a small number of hospitals to choose from, as well as urban areas with quite a large number of hospitals. It therefore seems reasonable to assume that the respondents are representative with respect to urbanization but not with respect to age. Older people might not use the internet as frequently as younger people. Therefore, the number of respondents who find government websites to be the most important source of quality information could have been underestimated. There are crucial and unanswered research questions that result from our empirical findings. (1) How can health insurers channel patients towards preferred providers in a way that patients are benefited, for instance by including GPs in their purchasing strategies? (2) What is the role of the government in relation to the provision of healthcare quality information within a system of managed competition, as their information is considered much less important than information provided by care providers? We encourage future research aimed at answering these questions, because this information is crucial to the creation of appropriate incentives within the system of managed competition, and a well-functioning system of managed competition will ultimately benefit the patients, as it involves incentives for care providers to increase healthcare quality and to produce at the lowest cost per unit of quality.

\section{Acknowledgements}

No sources of funding were used to conduct this study or to prepare this manuscript. The authors declare that they have no conflicts of interest relevant to the content of this article. We gratefully acknowledge the comments and suggestions of four anonymous reviewers and those of the Associate Editor Tim Wrightson. RB was responsible for the development of the survey, data collection, and data analysis. Both authors interpreted and discussed the results and their implications, and drafted and wrote the article. RB is the guarantor for the overall content.

\section{[APPENDIX]}


Bes, R.E., Berg, B. van den. Ranking sources of hospital quality information for orthopedic surgery patients: consequences for the system of managed competition. The Patient: PatientCentered Outcomes Research: 2013, 6(2), 75-80

\section{REFERENCES}

1. Enthoven AC, Van de Ven WPMM. Going Dutch—managedcompetition health insurance in the Netherlands. N Engl J Med.

2007;357(24):2421-3.

2. Van den Berg B, Van Dommelen P, Stam P, Laske-Aldershof T, Buchmueller T, Schut FT. Preferences and choices for care and health insurance. Soc Sci Med. 2008;66:2448-59.

3. Delnoij D, Van Merode G, Paulus A, Groenewegen P. Does general practitioner gatekeeping curb health care expenditure? J Health Serv Res Policy. 2000;5(1):22-6.

4. Boonen LHHM, Schut FT, Koolman X. Consumer channeling by health insurers: natural experiments with preferred providers in the Dutch pharmacy market. Health Econ. 2008;17:299-316.

5. Sorensen AT. Insurer-hospital bargaining: negotiated discounts in post-deregulation Connecticut. J Ind Econ. 2003;51(4):469-90.

6. Van de Ven WPMM, Schut FT. Managed competition in the Netherlands: still work-inprogress. Health Econ. 2009;18:253-5.

7. Delnoij D, Te Asbroek G, Arah OA. Made in the USA: the import of American Consumer Assessment of Health Plan Surveys (CAHPS) into the Dutch social insurance system. Eur J Public Health. 2006;16(6):652-9.

8. Van der Maat M, De Jong JD. Internet meest gebruikte informatiebron bij zoeken naar passende zorgverzekering. Utrecht: NIVEL; 2008.

9. Hibbard JH, Peters E, Slovic P, Finucane ML, Tusler M. Making health care report cards easier to use. Jt Comm J Qual Improv.

2001;27:591-604.

10. Hibbard JH, Slovic P, Peters E, Finucane ML. Strategies for reporting health plan information to consumers: evidence from controlled studies. Health Serv Res. 2002;37(2):291-313.

11. Meijer A. Vreemde ogen dwingen. Maatschappelijke controle in de publieke sector via internet. Den Haag: Boom Juridische Uitgevers; 2004.

12. Van der Star SM, Van den Berg B. Individual responsibility and health-risk behaviour: a contingent valuation study from the ex ante societal perspective. Health Policy. 2011;101:300-11.

13. Central Bureau of Statistics. Homepage. http://www.cbs.nl. Den Haag: Central Bureau of Statistics; 2009.

14. Dutch Health Care Authority. Richting geven aan keuzes. Kunnen verzekeraars consumenten stimuleren naar gecontrascteerde zorgaanbieders te gaan? [Giving direction to choices. Can insurers stimulate consumers to go to contracted care providers?] Utrecht: Dutch Health Care Authority; 2007.

15. de Groot I, Otten W, Smeets H, Marang-van de Mheen P. Is the impact of hospital performance data greater in patients who have compared hospitals? BMC Health Serv Res. 2011;11:214.

16. Marshall MN, Shekelle PG, Leatherman S, Brook $\mathrm{RH}$. The public release of performance data. What do we expect to gain? A review of the evidence. J Am Med Assoc. 2000;283(14):1866-73.

17. Marshall MN, McLoughlin V. How do patients use information on providers? $\mathrm{Br}$ Med J. 2010;341:1255-7.

18. Dijs-Elzinga J, Otten W, Versluijs M, Smeets $\mathrm{H}$, Kievit J, Vree R, et al. Choosing a hospital for surgery: the importance of information on quality of care. Med Decis Making. 2010;30:544-55.

19. Edgman-Levitan S, Cleary PD. What information do consumers want and need? Health Affairs. 1996;15(4):42-56.

20. Hibbard JH, Jewett JJ. Will quality report cards help consumers? Health Affairs. 1997;16(3):218-28.

21. Mosca I, Schut-Welkzijn A. Choice determinants of the mobility in the Dutch health insurance market. Eur J Health Econ.

2008;9:261-4.

22. Varkevisser M, Van der Geest SA. Why do patients bypass the nearest hospital? An empirical analysis for orthopaedics care and neurosurgery in the Netherlands. Eur J Health Econ. 
Bes, R.E., Berg, B. van den. Ranking sources of hospital quality information for orthopedic surgery patients: consequences for the system of managed competition. The Patient: PatientCentered Outcomes Research: 2013, 6(2), 75-80

2007;8(3):287-95.

23. Boonen LHHM. Consumer channeling in health care: (im)possible? Rotterdam: Erasmus Universiteit Rotterdam; 2009.

24. Frewer LJ, Howard C, Hedderly D, Sheperd R. What determines trust in information about food-related risks? Underlying psychological constructs. Risk Anal. 1996;16(4):47386.

TABLE AND APPENDIX

Table 1 Sources of hospital quality information ranked in order of importance (based on respondent feedback, $n=108$ )

\begin{tabular}{lll}
\hline Source & $\begin{array}{l}\text { Most important } \\
(\%)\end{array}$ & $\begin{array}{l}\text { Least important } \\
(\%)\end{array}$ \\
\hline Own experience & 43.5 & 1.9 \\
GP & 34.3 & 1.9 \\
Patient/consumer organization & 7.4 & 1.9 \\
Friends/family & 5.6 & 19.4 \\
Government websites & 5.6 & 16.7 \\
Health insurer & 3.7 & 15.7 \\
Ranking in newspaper/journal & 0.0 & 42.6 \\
\hline
\end{tabular}

Most important (\%) and Least important (\%) values for particular sources show the proportions of the respondents who considered this source to be the most and least important source of hospital quality information, respectively

\section{Appendix: survey questions}

The box below presents seven sources of hospital quality information.

\begin{tabular}{|ll|}
\hline 1. Health insurer & 5. Patient/consumer organization \\
2. Friends/family & 6. GP \\
3. Own experience & 7. Government websites \\
4. Ranking in national newspaper/journal & \\
\hline
\end{tabular}

Please indicate which source you find the most important and which one the least important? (Please select one number from the box indicating a source of hospital quality information)

The source I find most important :

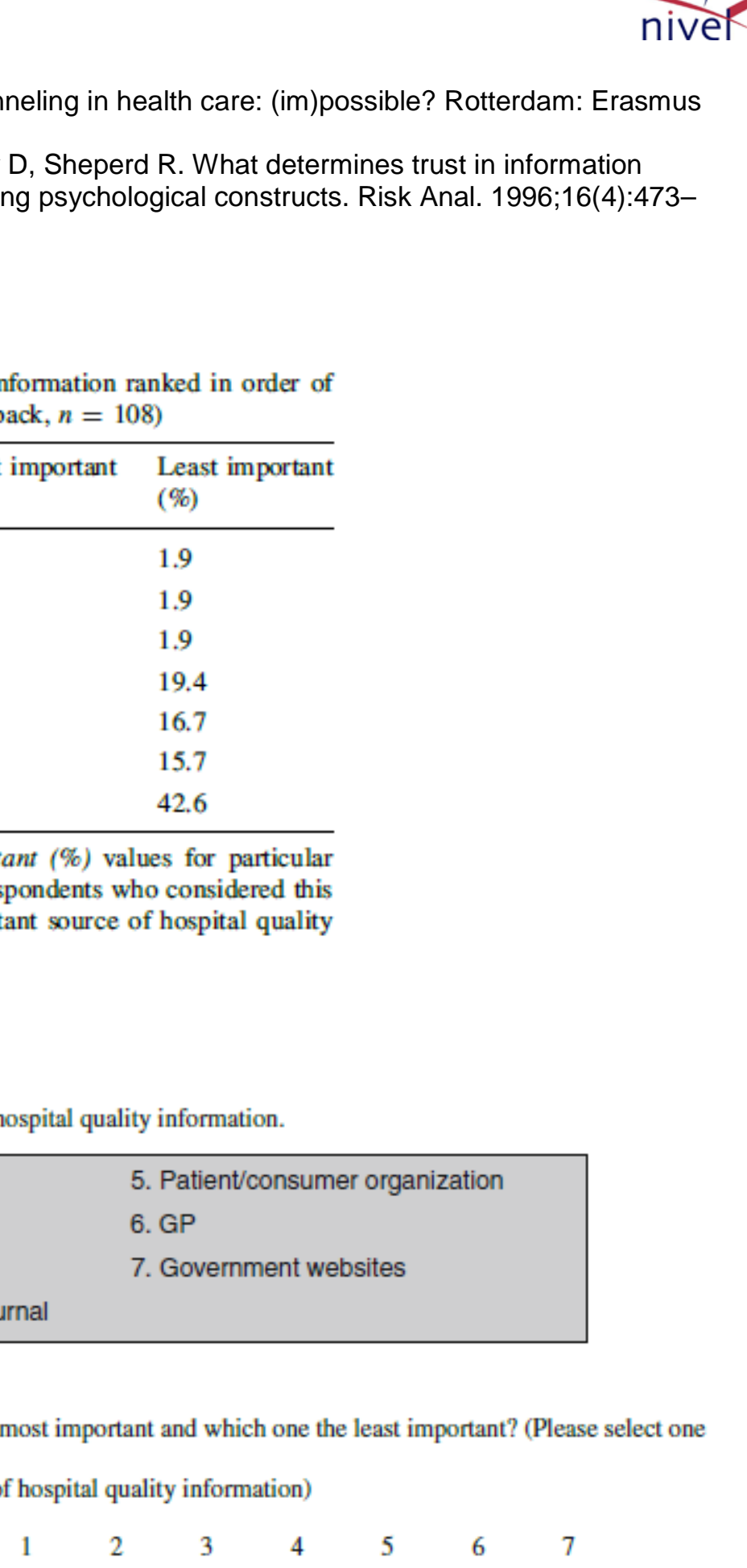

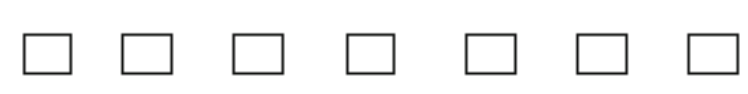

$\begin{array}{lllllll}1 & 2 & 3 & 4 & 5 & 6 & 7\end{array}$

The source I find least important : 